\title{
Analisis Keberhasilan Free Throw Pada Atlet Bolabasket Putra Ikor Unesa Ditinjau Dari Segi Biomekanika
}

\author{
Agil Yusqi Asmawana ${ }^{a}$ Himawan Wismanadi ${ }^{*}$ \\ Universitas Negeri Surabaya, Jl. Lidah Wetan, Surabaya 60213, Indonesia
}

Corresponding author: Himawanwismanadi@unesa.ac.id

A R T I C LE INFO

Article history:

Received 04 April 2019

Received in revised form 14

April 2019

Accepted 28 April 2019

Keywords:

Analysis, basketball, free throw,

biomechanics

\begin{abstract}
A B S T RA C T
The success of free throw is important in playing basketball. This is because the free throw is the opportunity for players to get score that is not guarded by the opponent. Failure of free throw can be caused by incorrect of the technique.

This research aims to determine the description of the success of free throws in male basketball athletes IKOR UNESA in terms of biomechanics.

This research method is descriptive analysis. The subjects of this study were 5 male athletes from IKOR UNESA whom each doing (performed) free throws 3 times. The results of the free throw were recorded using a camera (video) then were analyzed using dartfish software. The analysis focused on the arm angle, leg angle, throw angle and speed.

The results of the analysis show that the arm angle close to $90^{\circ}$ do not necessarily determine the success of the free throw if it is not accompanied by other factors. The angle of the leg that forms a knee bend between $90^{\circ}-120^{\circ}$ can determine the success of the free throw. The throw or release angle that forms a $49^{\circ}-55^{\circ}$ angle results in better free throw shots. The speed factor does not directly affect the success of the free throw if it is not added by other factors such as the height of the ball and the distance of the hand to the ring when doing a free throw (bisa juga: when a free throw is performed).
\end{abstract}

\section{Pendahuluan}

Bolabasket sudah menjadi salah satu cabang olahraga yang cukup populer di Indonesia selain cabang olahraga sepakbola. Olahraga bolabasket merupakan olahraga yang memasyarakat, mulai dari anak-anak hingga orang dewasa, baik lakilaki maupun perempuan dapat memainkannya. Bahkan hampir di setiap sekolah-sekolah maupun perguruan tinggi memiliki fasilitas lapangan bolabasket.

Permainan bolabasket merupakan permainan tim atau beregu. Dalam permainan bolabasket baku, setiap tim memiliki lima pemain di lapangan (Oliver, 2007 : 8). Setiap pemain bolabasket harus memiliki teknik dasar yang baik dan benar agar tercipta permainan tim yang baik. Keterampilan teknik dasar bolabasket yang harus dikuasai antara lain:

1. Penguasaan Bola (Ball Handling),

2. Melempar dan Menangkap Bola (Passing and Catching),

3. Menggiring Bola (Dribbling),

4. Menembak Bola (Shooting),

5. Gerakan Berporos (Pivot),

6. Merayah Bola (Rebound),

7. Step (Lay up shoot),

8. Stop Dengan Bola (Stopping),

9. Gerak Tipu (Fake and Faints),

10. Tipping.

(Rastafari dkk,2005:7-8)

Tujuan dari permainan bolabasket adalah memasukkan bola ke dalam keranjang. Maka teknik dasar yang harus dilakukan adalah menembak bola (shooting). Apabila dalam satu 
tim semua pemain memiliki kemampuan shooting yang baik akan memudahkan pelatih untuk melakukan rotasi pemain dan tidak bergantung kepada satu individu saja.

Untuk dapat melakukan shooting yang baik dibutuhkan latihan yang ekstra dan dimulai dengan persiapan untuk melakukan tembakan. Menurut Abidin (dalam skripsi Rizki:2010) persiapan untuk melakukan tembakan dengan baik dalam permainan bolabasket, yaitu posisi tangan, pandangan, keseimbangan dan irama tembakan.

Dalam permainan bolabasket shooting dapat menghasilkan 1 angka, 2 angka, dan 3 angka. Shooting 1 angka diperoleh dari posisi free throw (tembakan bebas). Shooting 2 angka diperoleh dari perimeter area baik berupa lay-up, jump shoot, set shoot, maupun slam dunk. Sementara shooting 3 angka diperoleh dari luar area perimeter.

Penerapan taktik dalam permainan bolabasket seringkali menyebabkan terjadinya pelanggaran (violations) maupun kesalahan (foul). Kesalahan (foul) adalah penyimpangan dari peraturan yang menyebabkan persinggungan dengan lawan atau tingkah laku pemain yang tidak sopan (Perbasi, 2000). Di dalam permainan bolabasket, dengan 10 pemain yang bergerak dengan cepat dalam jarak yang terbatas, persinggungan tidak dapat dihindari sehingga menimbulkan kesalahan (foul).

Kemenangan sebuah tim terkadang ditentukan oleh keberhasilan dalam melakukan tembakan bebas atau free throw, dengan semakin baik mengeksekusi free throw semakin bertambah pula poin atau nilai tim tersebut, dengan nilai yang tinggi tersebut akan dinyatakan sebagai pemenang. Menurut Kosasih (2008) bahwa tembakan free throw sangat menentukan kemenangan atau kekalahan di dalam pertandingan, maka latihlah free throw didalam setiap latihan.

Free throw adalah kesempatan yang diberikan kepada seorang pemain untuk mencetak 1 (satu) angka, tidak dijaga, dari posisi dibelakang garis free throw dan di dalam setengah lingkaran (PERBASI, 2010:51). Dalam permainan bolabasket free throw memiliki pengaruh yang cukup signifikan apabila dalam pertandingan yang ketat. Pemain yang memiliki teknik free throw yang baik dan benar akan mampu membantu tim dalam meraih kemenangan dalam suatu pertandingan.

Kegagalan melakukan free throw dapat diakibatkan oleh fundamental teknik shooting yang salah. Oleh karena itu free throw perlu untuk di analisis. Analisis gerakan dalam olahraga sangat perlu dilakukan oleh pelatih maupun ahli biomekanik untuk memperbaiki gerakan yang salah (Pate, 1993: 177). Salah satu cara untuk menganalisis gerakan free throw dalam bolabasket yaitu menggunakan software dartfish dengan memperhatikan prinsip-prinsip biomekanika.

Berdasarkan latar belakang diatas maka peneliti ingin melakukan analisis keberhasilan free throw pada atlet bolabasket putra IKOR UNESA ditinjau dari segi biomekanika.

\section{Metode Penelitian}

Jenis penelitian ini adalah penelitian deskriptif analisis. Penelitian analisis deskriptif adalah suatu jenis penelitian yang bertujuan untuk menyelidiki keadaan, kondisi, yang hasilnya dipaparkan dalam laporan penelitian (Arikunto, 2010: 3).Penelitian ini bertujuan untuk menganalisa dan menyajikan fakta secara sistematik sehingga dapat dipahami dengan lebih mudah. Selain itu untuk memberikan gambaran analisis keberhasilan free throw melalui rekaman video dengan menggunakan software dartfish.

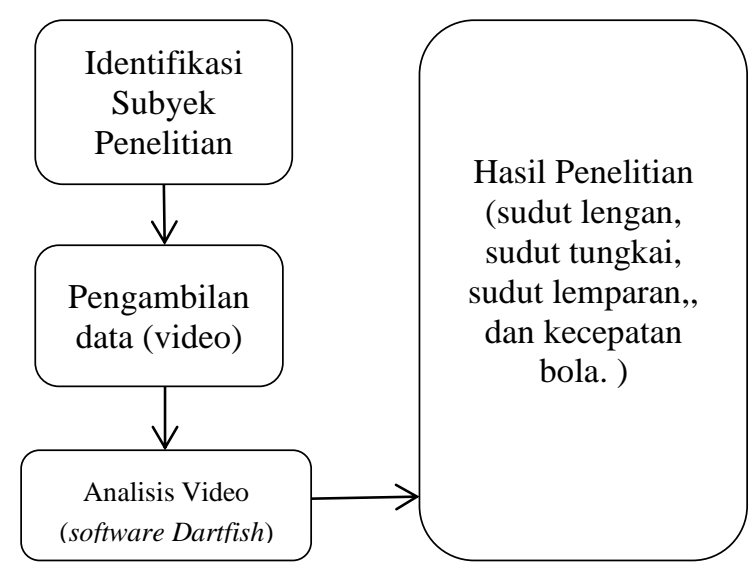

Gambar 1. Desain penelitian 
Populasi dari penelitian ini adalah semua mahasiswa IKOR yang mengikuti kegiatan basket jurusan berjumlah 20 orang. dalam penelitian ini menggunakan teknik pengambilan sampel "Purposive Sampling" karena penentuan satuan sampel dengan pertimbangan khusus sehingga layak dijadikan sampel (Noor, 2011: 155). Sampel yang digunakan untuk subjek penelitian sebanyak 5 orang. Karena dapat mewakili setiap posisi pemain pada permainan bola basket dan setiap pemain mempunyai kemungkinan yang sama besar untuk memperoleh free throw dalam suatu pertandingan. Instrumen penelitian yang dibutuhkan dalam penelitian ini adalah software dartfish dengan alat pendukung berupa laptop, alat tulis, dan 1 kamera DSLR atau bisa juga handycamera.

Kamera dengan spesifikasi nikon $42 \mathrm{X}$ wide optical zoom ED VR 4,3 - 180 MM 1:3 - 5 diletakkan tegak lurus antara testee dengan ring. Hal ini dilakukan agar memperoleh gambar secara jelas. Kamera ditempatkan disebelah kanan karena semua testee menggunakan tangan kanan saat melakukan free throw. Agar dapat lebih jelas saat melakukan analisis tahapan gerakan-gerakan saat melakukan free throw. Melakukan analisis gerak free throw dibutuhkan software dartfish. Maka kegiatan yang harus dilakukan adalah :

1. Tahap Persiapan

a. Mempersiapkan perlengkapan penelitian antara lain, laptop, kamera digital, alat tulis, dan lain-lain.

b. Meletakkan kamera tegak lurus dari testee dan memeriksa kondisi kamera digital yang digunakan untuk mengambil data.

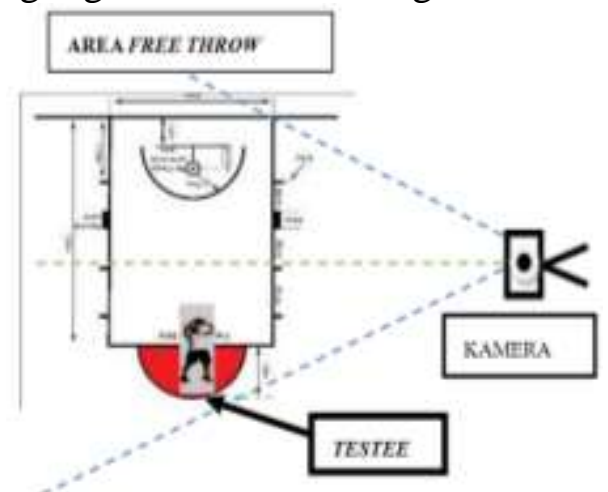

Gambar 2. Letak Kamera
2. Tahap Pengumpulan Data

Setelah tahap persiapan selesai, maka tahap berikut adalah pengumpulan data berupa tes free throw, langkah-langkahnya adalah sebagai berikut :

a. Testee ditempatkan di garis free throw dan bersiap melakukan gerakan shooting. Tahapan gerakan free throw menurut Hal Wissel (1996: 53) adalah :

1. Fase Persiapan

a. Penegasan yang positif

b. Letakkan kaki untuk menembak sedikit di luar tanda

c. Lakukan dengan rutin

d. Sikap yang seimbang

e. Tangan yang tidak menembak di bawah bola

f. Tangan menembak di belakang bola

g. Ibu jari rileks

h. Siku masuk ke dalam

i. Bola antara telinga dan bahu

j. Bahu rileks

k. Napas dalam (rileks)

1. Visualkan tambahan yang berhasil

m. Konsentrasikan pada target

2. Fase Pelaksanaan

1. Lihat target

2. Ucapkan kata - kata kunci secara berirama

3. Rentangkan kaki, punggung, bahu

4. Rentangkan siku

5. Lenturkan pinggang dan jari - jari ke depan

6. Lepaskan jari telunjuk

7. Tangan penyeimbang pada bola sampai terlepas

3. Fase Follow Through

1. Lihat target

2. Tangan lengan terentang

3. Jari telunjuk menunjuk pada target

4. Telapak tangan ke bawah saat shooting

5. Seimbangkan dengan telapak tangan ke atas

6. Posisi lengan tetap di atas sampai bola masuk ke dalam ring 
b. Testee melakukan gerakan free throw sebanyak tiga kali.

c. Hasil dari tes tersebut akan direkam menggunakan kamera, kemudian data dimasukkan kedalam laptop untuk dianalisis menggunakan software dartfish. Agar dapat diketahui kecepatan bola, sudut tungkai, sudut siku, dan sudut lemparan pada saat melakukan gerakan free throw.

Dalam penelitian ini teknik analisis datanya menggunakan prinsip-prinsip bomekanika dengan bantuan software dartfish sebagai alat bantu pengukuran. Hasil rekaman tes free throw kemudian dimasukkan kedalam laptop. Video hasil rekaman diubah formatnya dalam bentuk avid an setelah itu dibuat dalam bentuk gerakangerakan clip (videoclip). Hasil rekaman dimasukkan dengan menggunakan card reader dan menggunakan fasilitas DV import. Setelah itu untuk melakukan analisis maka digunakan fasilitas analyzer. Analisis gerak difokuskan pada kecepatan bola, sudut tungkai, sudut siku, dan sudut lemparan pada saat melakukan free throw.

\section{Hasil Penelitian dan Pembahasan}

\section{Hasil Penelitian}

Dalam bab ini akan dikemukakan beberapa data yang diperoleh dari hasil penelitian. Data dalam penelitian ini adalah hasil dari analisis tahapan-tahapan free throw. Data yang diperoleh dalam penelitian merupakan serangkaian gerakan free throw yang diambil dari subjek penelitian selama penelitian berlangsung. Beberapa hasil pengukuran yang disajikan dalam penelitian ini antara lain:

1. Sudut lengan

2. Sudut tungkai

3. Sudut lemparan

4. Tinggi bola

5. Jarak

6. Kecepatan awal bola.

Tabel 1. Hasil Pengukuran Subjek Penelitian Pertama

\begin{tabular}{|l|c|c|c|}
\hline Percobaan & 1 & 2 & 3 \\
\hline Sudut lengan $\left(^{\circ}\right)$ & 64,7 & 62,4 & 70,1 \\
\hline
\end{tabular}

\begin{tabular}{|c|c|c|c|c|}
\hline \multicolumn{2}{|c|}{ Sudut tungkai $\left({ }^{\circ}\right)$} & 107,8 & 98,1 & 100,8 \\
\hline \multicolumn{2}{|c|}{ Sudut lemparan $\left(^{\circ}\right)$} & 56,7 & 60,4 & 53,1 \\
\hline \multirow[t]{2}{*}{$\begin{array}{l}\text { Tinggi bola } \\
\text { (m) }\end{array}$} & $\begin{array}{l}\text { Lepas } \\
\text { dari } \\
\text { tangan }\end{array}$ & 2,34 & 2,28 & 2,24 \\
\hline & Maks & 2,20 & 2,42 & 2,28 \\
\hline \multirow{2}{*}{ Jarak } & A & 4,60 & 4,60 & 4,60 \\
\hline & B & 4,80 & 4,79 & 4,77 \\
\hline \multicolumn{2}{|c|}{ Kecepatan awal $(\mathrm{m} / \mathrm{s})$} & 7,5 & 6,7 & 7,5 \\
\hline \multicolumn{2}{|l|}{ Keterangan } & Gagal & Gagal & Masuk \\
\hline
\end{tabular}

Berdasarkan tabel 1. dapat dijelaskan dalam pelaksanaan free throw pada subjek penelitian yang pertama, pada percobaan pertama pada jarak 4,60 $\mathrm{m}$ posisi tubuh saat melakukan free throw posisi tungkai membentuk sudut $107,8^{\circ}$ dan jarak tangan dari keranjang saat bola lepas dari tangan adalah $4,80 \mathrm{~m}$. Posisi lengan membentuk sudut $64,7^{\circ}$, tinggi bola saat lepas dari tangan $2,34 \mathrm{~m}$ dan memperoleh sudut lemparan $56,7^{\circ}$ menghasilkan kecepatan awal bola $7,5 \mathrm{~m} / \mathrm{s}$ dengan tinggi maksimum bola mencapai 2,20 m dan memperlihatkan bola gagal masuk ke dalam keranjang.

Pada percobaan free throw yang kedua pada jarak 4,60 m posisi tubuh saat melakukan free throw posisi tungkai membentuk sudut $98,1^{\circ}$ dan jarak tangan dari keranjang saat bola lepas dari tangan adalah 4,79 m. Posisi lengan membentuk sudut $62,4^{\circ}$, tinggi bola saat lepas dari tangan $2,28 \mathrm{~m}$ dan memperoleh sudut lemparan $60,4^{\circ}$ menghasilkan kecepatan awal bola $6,7 \mathrm{~m} / \mathrm{s}$ dengan tinggi maksimum bola mencapai $2,42 \mathrm{~m}$ dan memperlihatkan bola gagal masuk ke dalam keranjang.

Pada percobaan free throw yang ketiga pada jarak 4,60 m posisi tubuh saat melakukan free throw posisi tungkai membentuk sudut $100,8^{\circ}$ dan jarak tangan dari keranjang saat bola lepas dari tangan adalah 4,77 m. Posisi lengan membentuk sudut $70,1^{\circ}$, tinggi bola saat lepas dari tangan 2,24 $\mathrm{m}$ dan memperoleh sudut lemparan 53,1 $1^{\circ}$ menghasilkan kecepatan awal bola $7,5 \mathrm{~m} / \mathrm{s}$ dengan tinggi maksimum bola mencapai 2,28 $\mathrm{m}$ dan memperlihatkan bola masuk ke dalam keranjang.

Tabel 2. Hasil Pengukuran Subjek Penelitian Kedua

\begin{tabular}{|l|c|c|c|}
\hline Percobaan & 1 & 2 & 3 \\
\hline Sudut lengan $\left(^{\circ}\right)$ & 88,1 & 96,1 & 90,5 \\
\hline Sudut tungkai $\left(^{\circ}\right)$ & 108,2 & 112,9 & 108,1 \\
\hline Sudut lemparan $\left(^{\circ}\right)$ & 51,9 & 50,5 & 49,5 \\
\hline
\end{tabular}




\begin{tabular}{|l|l|c|c|c|}
\hline \multirow{2}{*}{$\begin{array}{l}\text { Tinggi bola } \\
(\mathrm{m})\end{array}$} & $\begin{array}{l}\text { Lepas } \\
\text { dari } \\
\text { tangan }\end{array}$ & 2,70 & 2,58 & 2,75 \\
\cline { 2 - 5 } & Maks & 1,62 & 1,58 & 1,48 \\
\hline \multirow{2}{*}{ Jarak } & $\mathrm{A}$ & 4,60 & 4,60 & 4,60 \\
\cline { 2 - 5 } & $\mathrm{B}$ & 4,66 & 4,50 & 4,64 \\
\hline \multicolumn{2}{|l|}{ Kecepatan awal (m/s) } & 7,2 & 6,9 & 7,3 \\
\hline \multicolumn{2}{|l}{ Keterangan } & Gagal & Gagal & Masuk \\
\hline
\end{tabular}

Keterangan:

$\mathrm{A}=$ Jarak saat melakukan free throw

$\mathrm{B}=$ Jarak tangan dengan ring saat melakukan free throw

Berdasarkan tabel 2 dapat dijelaskan dalam pelaksanaan free throw pada subjek penelitian yang kedua, pada percobaan pertama pada jarak $4,60 \mathrm{~m}$ posisi tubuh saat melakukan free throw posisi tungkai membentuk sudut $108,2^{\circ}$ dan jarak tangan dari keranjang saat bola lepas dari tangan adalah 4,66 m. Posisi lengan membentuk sudut $88,1^{\circ}$, tinggi bola saat lepas dari tangan $2,70 \mathrm{~m}$ dan memperoleh sudut lemparan $51,9^{\circ}$ menghasilkan kecepatan awal bola $7,2 \mathrm{~m} / \mathrm{s}$ dengan tinggi maksimum bola mencapai $1,62 \mathrm{~m}$ dan memperlihatkan bola gagal masuk ke dalam keranjang.

Pada percobaan free throw yang kedua pada jarak 4,60 m posisi tubuh saat melakukan free throw posisi tungkai membentuk sudut $112,9^{\circ}$ dan jarak tangan dari keranjang saat bola lepas dari tangan adalah $4,50 \mathrm{~m}$. Posisi lengan membentuk sudut $96,1^{\circ}$, tinggi bola saat lepas dari tangan 2,58 $m$ dan memperoleh sudut lemparan $50,5^{\circ}$ menghasilkan kecepatan awal bola $6,9 \mathrm{~m} / \mathrm{s}$ dengan tinggi maksimum bola mencapai $1,58 \mathrm{~m}$ dan memperlihatkan bola gagal masuk ke dalam keranjang.

Pada percobaan free throw yang ketiga pada jarak 4,60 m posisi tubuh saat melakukan free throw posisi tungkai membentuk sudut $108,1^{\circ}$ dan jarak tangan dari keranjang saat bola lepas dari tangan adalah 4,64 m. Posisi lengan membentuk sudut $90,5^{\circ}$, tinggi bola saat lepas dari tangan 2,75 $\mathrm{m}$ dan memperoleh sudut lemparan 49,5 menghasilkan kecepatan awal bola 7,3 m/s dengan tinggi maksimum bola mencapai $1,48 \mathrm{~m}$ dan memperlihatkan bola masuk ke dalam keranjang.

Tabel 3. Hasil Pengukuran Subjek Penelitian Ketiga

\begin{tabular}{|c|c|c|c|c|}
\hline \multicolumn{2}{|l|}{ Percobaan } & 1 & 2 & 3 \\
\hline \multicolumn{2}{|c|}{ Sudut lengan $\left(^{\circ}\right)$} & 83,1 & 79,6 & 75,9 \\
\hline \multicolumn{2}{|c|}{ Sudut tungkai $\left({ }^{\circ}\right)$} & 100,2 & 99,3 & 97,8 \\
\hline \multicolumn{2}{|c|}{ Sudut lemparan $\left(^{\circ}\right)$} & 55,0 & 54,0 & 56,0 \\
\hline $\begin{array}{l}\text { Tinggi bola } \\
\text { (m) }\end{array}$ & $\begin{array}{l}\text { Lepas } \\
\text { dari } \\
\text { tangan }\end{array}$ & 2,51 & 2,40 & 2,45 \\
\hline
\end{tabular}

\begin{tabular}{|l|c|c|c|c|}
\hline & Maks & 1,93 & 1,99 & 2,04 \\
\hline \multirow{2}{*}{ Jarak } & $\mathrm{A}$ & 4,60 & 4,60 & 4,60 \\
\cline { 2 - 5 } & $\mathrm{B}$ & 4,50 & 4,55 & 4,62 \\
\hline \multicolumn{2}{|l|}{ Kecepatan awal (m/s) } & 7,3 & 7,3 & 7,8 \\
\hline \multicolumn{2}{|l}{ Keterangan } & Masuk & Masuk & Gagal \\
\hline
\end{tabular}

Keterangan:

$\mathrm{A}=$ Jarak saat melakukan free throw

$\mathrm{B}=$ Jarak tangan dengan ring saat melakukan free throw

Berdasarkan tabel 3 dapat dijelaskan dalam pelaksanaan free throw pada subjek penelitian yang ketiga, pada percobaan pertama pada jarak 4,60 m posisi tubuh saat melakukan free throw posisi tungkai membentuk sudut $100,2^{\circ}$ dan jarak tangan dari keranjang saat bola lepas dari tangan adalah $4,50 \mathrm{~m}$. Posisi lengan membentuk sudut $83,1^{\circ}$, tinggi bola saat lepas dari tangan $2,51 \mathrm{~m}$ dan memperoleh sudut lemparan $55,0^{\circ}$ menghasilkan kecepatan awal bola $7,3 \mathrm{~m} / \mathrm{s}$ dengan tinggi maksimum bola mencapai $1,93 \mathrm{~m}$ dan memperlihatkan bola masuk ke dalam keranjang.

Pada percobaan free throw yang kedua pada jarak 4,60 m posisi tubuh saat melakukan free throw posisi tungkai membentuk sudut $99,3^{\circ}$ dan jarak tangan dari keranjang saat bola lepas dari tangan adalah 4,55 m. Posisi lengan membentuk sudut $79,6^{\circ}$, tinggi bola saat lepas dari tangan 2,40 $\mathrm{m}$ dan memperoleh sudut lemparan 54,0 menghasilkan kecepatan awal bola $7,5 \mathrm{~m} / \mathrm{s}$ dengan tinggi maksimum bola mencapai $1,99 \mathrm{~m}$ dan memperlihatkan bola masuk ke dalam keranjang.

Pada percobaan free throw yang ketiga pada jarak 4,60 m posisi tubuh saat melakukan free throw posisi tungkai membentuk sudut $97,8^{\circ}$ dan jarak tangan dari keranjang saat bola lepas dari tangan adalah 4,62 m. Posisi lengan membentuk sudut $75,9^{\circ}$, tinggi bola saat lepas dari tangan 2,45 $\mathrm{m}$ dan memperoleh sudut lemparan 56,0 menghasilkan kecepatan awal bola 7,8 m/s dengan tinggi maksimum bola mencapai $2,04 \mathrm{~m}$ dan memperlihatkan bola gagal masuk ke dalam keranjang.

\section{Tabel 4. Hasil Pengukuran Subjek Penelitian} Keempat

\begin{tabular}{|c|c|c|c|c|}
\hline \multicolumn{2}{|l|}{ Percobaan } & 1 & 2 & 3 \\
\hline \multicolumn{2}{|c|}{ Sudut lengan $\left(^{\circ}\right)$} & 85,0 & 84,5 & 86,0 \\
\hline \multicolumn{2}{|c|}{ Sudut tungkai $\left({ }^{\circ}\right)$} & 110,7 & 104,0 & 108,0 \\
\hline \multicolumn{2}{|c|}{ Sudut lemparan $\left({ }^{\circ}\right)$} & 53,0 & 53,5 & 56,5 \\
\hline \multirow[t]{2}{*}{$\begin{array}{l}\text { Tinggi bola } \\
\text { (m) }\end{array}$} & $\begin{array}{l}\text { Lepas } \\
\text { dari } \\
\text { tangan }\end{array}$ & 2,63 & 2,69 & 2,52 \\
\hline & Maks & 1,94 & 1,89 & 1,90 \\
\hline \multirow{2}{*}{ Jarak } & A & 4,60 & 4,60 & 4,60 \\
\hline & B & 4,69 & 4,80 & 4,75 \\
\hline \multicolumn{2}{|c|}{ Kecepatan awal $(\mathrm{m} / \mathrm{s})$} & 7,2 & 7,5 & 7,5 \\
\hline
\end{tabular}




\begin{tabular}{|l|c|c|c|}
\hline Keterangan & Masuk & Gagal & Gagal \\
\hline
\end{tabular}

Keterangan:

A = Jarak saat melakukan free throw

$\mathrm{B}=$ Jarak tangan dengan ring saat melakukan free throw

Berdasarkan tabel 4 dapat dijelaskan dalam pelaksanaan free throw pada subjek penelitian yang keempat, pada percobaan pertama pada jarak 4,60 $\mathrm{m}$ posisi tubuh saat melakukan free throw posisi tungkai membentuk sudut $110,7^{\circ}$ dan jarak tangan dari keranjang saat bola lepas dari tangan adalah 4,69 m. Posisi lengan membentuk sudut $85,0^{\circ}$, tinggi bola saat lepas dari tangan $2,63 \mathrm{~m}$ dan memperoleh sudut lemparan $53,0^{\circ}$ menghasilkan kecepatan awal bola $7,2 \mathrm{~m} / \mathrm{s}$ dengan tinggi maksimum bola mencapai $1,94 \mathrm{~m}$ dan memperlihatkan bola masuk ke dalam keranjang.

Pada percobaan free throw yang kedua pada jarak 4,60 m posisi tubuh saat melakukan free throw posisi tungkai membentuk sudut $104,0^{\circ}$ dan jarak tangan dari keranjang saat bola lepas dari tangan adalah $4,80 \mathrm{~m}$. Posisi lengan membentuk sudut $84,5^{\circ}$, tinggi bola saat lepas dari tangan 2,69 $\mathrm{m}$ dan memperoleh sudut lemparan 53,5 menghasilkan kecepatan awal bola 7,5 m/s dengan tinggi maksimum bola mencapai $1,89 \mathrm{~m}$ dan memperlihatkan bola masuk ke dalam keranjang.

Pada percobaan free throw yang ketiga pada jarak 4,60 m posisi tubuh saat melakukan free throw posisi tungkai membentuk sudut $108,0^{\circ}$ dan jarak tangan dari keranjang saat bola lepas dari tangan adalah 4,75 m. Posisi lengan membentuk sudut $86,0^{\circ}$, tinggi bola saat lepas dari tangan 2,52 $\mathrm{m}$ dan memperoleh sudut lemparan 56,5 menghasilkan kecepatan awal bola 7,5 m/s dengan tinggi maksimum bola mencapai $1,90 \mathrm{~m}$ dan memperlihatkan bola gagal masuk ke dalam keranjang.

Tabel 5. Hasil Pengukuran Subjek Penelitian Kelima

\begin{tabular}{|c|c|c|c|c|}
\hline \multicolumn{2}{|l|}{ Percobaan } & 1 & 2 & 3 \\
\hline \multicolumn{2}{|c|}{ Sudut lengan $\left(^{\circ}\right)$} & 74,6 & 71,7 & 75,1 \\
\hline \multicolumn{2}{|c|}{ Sudut tungkai $\left({ }^{\circ}\right)$} & 103,1 & 103,0 & 106,6 \\
\hline \multicolumn{2}{|c|}{ Sudut lemparan $\left({ }^{\circ}\right)$} & 52,0 & 54,5 & 54,7 \\
\hline \multirow[t]{2}{*}{$\begin{array}{l}\text { Tinggi bola } \\
\text { (m) }\end{array}$} & $\begin{array}{l}\text { Lepas } \\
\text { dari } \\
\text { tangan }\end{array}$ & 2,50 & 2,52 & 2,60 \\
\hline & Maks & 1,76 & 1,88 & 1,87 \\
\hline \multirow{2}{*}{ Jarak } & $\mathrm{A}$ & 4,60 & 4,60 & 4,60 \\
\hline & B & 4,64 & 4,71 & 4,64 \\
\hline \multicolumn{2}{|c|}{ Kecepatan awal $(\mathrm{m} / \mathrm{s})$} & 7,3 & 7,2 & 7,3 \\
\hline \multicolumn{2}{|l|}{ Keterangan } & Masuk & Masuk & Masuk \\
\hline
\end{tabular}

Keterangan:

\section{$\mathrm{A}=$ Jarak saat melakukan free throw \\ $\mathrm{B}=$ Jarak tangan dengan ring saat melakukan free throw}

Berdasarkan tabel 5 dapat dijelaskan dalam pelaksanaan free throw pada subjek penelitian yang kelima, pada percobaan pertama pada jarak 4,60 $\mathrm{m}$ posisi tubuh saat melakukan free throw posisi tungkai membentuk sudut $103,1^{\circ}$ dan jarak tangan dari keranjang saat bola lepas dari tangan adalah 4,64 m. Posisi lengan membentuk sudut $74,6^{\circ}$, tinggi bola saat lepas dari tangan $2,50 \mathrm{~m}$ dan memperoleh sudut lemparan 52,0 $0^{\circ}$ menghasilkan kecepatan awal bola $7,3 \mathrm{~m} / \mathrm{s}$ dengan tinggi maksimum bola mencapai $1,76 \mathrm{~m}$ dan memperlihatkan bola masuk ke dalam keranjang.

Pada percobaan free throw yang kedua pada jarak $4,60 \mathrm{~m}$ posisi tubuh saat melakukan free throw posisi tungkai membentuk sudut $103,0^{\circ}$ dan jarak tangan dari keranjang saat bola lepas dari tangan adalah 4,71 m. Posisi lengan membentuk sudut $71,7^{\circ}$, tinggi bola saat lepas dari tangan 2,52 $\mathrm{m}$ dan memperoleh sudut lemparan 54,5 menghasilkan kecepatan awal bola 7,2 $\mathrm{m} / \mathrm{s}$ dengan tinggi maksimum bola mencapai $1,88 \mathrm{~m}$ dan memperlihatkan bola masuk ke dalam keranjang.

Pada percobaan free throw yang ketiga pada jarak 4,60 m posisi tubuh saat melakukan free throw posisi tungkai membentuk sudut $106,6^{\circ}$ dan jarak tangan dari keranjang saat bola lepas dari tangan adalah 4,64 m. Posisi lengan membentuk sudut $75,1^{\circ}$, tinggi bola saat lepas dari tangan 2,60 $\mathrm{m}$ dan memperoleh sudut lemparan 54,7 menghasilkan kecepatan awal bola 7,3 m/s dengan tinggi maksimum bola mencapai $1,87 \mathrm{~m}$ dan memperlihatkan bola masuk ke dalam keranjang.

\section{Pembahasan}

Sesuai dengan tujuan penelitian untuk menganalisis keberhasilan free throw, maka pembahasan akan difokuskan pada hasil shooting yang berhasil masuk ke dalam ring.

Table 6. Hasil pengukuran free throw yang berhasil masuk ke dalam ring.

\begin{tabular}{|c|c|c|c|}
\hline \multirow{2}{*}{$\begin{array}{c}\text { Subyek } \\
\text { penelitian }\end{array}$} & \multicolumn{3}{|c|}{ Percobaan yang berhasil } \\
\cline { 2 - 4 } & 1 & 2 & 3 \\
\hline 1 & Gagal & Gagal & Masuk \\
\hline 2 & Gagal & Gagal & Masuk \\
\hline 3 & Masuk & Masuk & Gagal \\
\hline 4 & Masuk & Gagal & Gagal \\
\hline 5 & Masuk & Masuk & Masuk \\
\hline
\end{tabular}

Menurut Hay (1978: 231) supaya dalam shooting itu berhasil maka siku harus berada pada 
sudut yang tepat agar bola dapat masuk dan "sudut optimum masuk adalah kurang lebih atau mendekati 90 "' (Hay, 1978: 231).

Berdasarkan pengukuran dengan total $15 \mathrm{kali}$ percobaan free throw dari 5 subyek peneliti dengan masing - masing 3 kali percobaan didapatkan rata-rata besarnya sudut lengan free throw yang berhasil masuk sebesar $78,71^{\circ}$, sedangkan yang gagal sebesar $79,67^{\circ}$. Dari data tersebut berarti rata-rata besarnya sudut lengan free throw yang gagal lebih mendekati $90^{\circ}$ daripada rata-rata besarnya sudut lengan free throw yang berhasil masuk. Namun besarnya sudut lengan bukan merupakan factor penentu utama keberhasilan free throw.

Faktor lain yang berpengaruh yakni sudut tungkai yang dibentuk. Sudut tungkai akan berpengaruh pada daya ledak berupa lemparan yang akan mempengaruhi daya laju bola. Menurut kosasih (2008) posisi kaki diusahakan "membuat sudut pada tekukan lutut antara $90^{\circ}-120^{\circ}$ ". Dari data sudut tungkai didapatkan rata-rata besarnya sudut tungkai free throw yang berhasil masuk sebesar $103,96^{\circ}$, sedangkan yang gagal sebesar $105,26^{\circ}$. Dari data sudut tungkai tersebut dapat diartikan bahwa dalam melakukan free throw perlu menekukkan kaki mendekati $103,96^{\circ}$ untuk mendapatkan hasil tembakan yang baik yaitu bola yang masuk ke dalam ring.

Factor besarnya sudut lemparan juga dapat mempengaruhi keberhasilan tembakan free throw. Dari data sudut lemparan didapatkan rata-rata besarnya sudut lemparan free throw yang berhasil masuk sebesar $53,23^{\circ}$, sedangkan yang gagal sebesar $55,07^{\circ}$. Hal ini sesuai dengan pendapat Shibukawa dalam Hay (1978: 233) "sudut pelepasan $49^{\circ}-55^{\circ}$ tentu tampak menjadi optimal jika kecepatan bola juga diperhitungkan, sudut pelepasan lebih besar dari 52 atau 53 derajat mungkin akan lebih baik.

Disamping itu, factor kecepatan juga tidak kalah penting dalam menentukan tingkat keberhasilan shooting (Hudson, 1982). Dari hasil analisis didapatkan data rata-rata kecepatan awal $(\mathrm{m} / \mathrm{s})$ free throw yang berhasil masuk sebesar 7,3 $\mathrm{m} / \mathrm{s}$, sedangkan yang gagal juga sama sebesar 7,3 $\mathrm{m} / \mathrm{s}$. Dari data tersebut dapat diartikan bahwa factor kecepatan tidak berpengaruh terhadap keberhasilan free throw dalam bola basket. Hal tersebut kemungkinan juga dipengaruhi oleh factor tinggi bola dan jarak tangan dengan ring saat melakukan free throw, sehingga factor kecepatan tidak secara langsung dapat mempengaruhi keberhasilan free throw jika tidak ditambah oleh factor lain seperti tinggi bola dan jarak tangan dengan ring saat melakukan free throw.

\section{Simpulan dan Rekomendasi}

Berdasarkan hasil penelitian dan pembahasan di atas, maka dapat disimpulkan :

1. Sudut lengan yang mendekati $90^{\circ}$ belum tentu menentukan keberhasilan free throw (bola masuk ring) jika tidak diiringi factor lain seperti sudut tungkai, sudut lemparan dan kecepatan laju bola.

2. Sudut tungkai yang membentuk tekukan lutut antara $90^{\circ}-120^{\circ}$ dapat menentukan keberhasilan free throw (bola masuk ring). Dan dalam penelitian ini rata-rata sudut tungkai yang berhasil melakukan free throw dan bola masuk ke dalam ring adalah $103,96^{\circ}$.

3. Sudut lemparan atau pelepasan yang membentuk sudut $49^{\circ}-55^{\circ}$ menghasilkan tembakan free throw yang lebih baik. Hal ini dibuktikan dari hasil penelitian ratarata besarnya sudut lemparan free throw yang berhasil masuk sebesar $53,23^{\circ}$, sedangkan yang gagal sebesar $55,07^{\circ}$.

4. Factor kecepatan tidak berpengaruh secara langsung terhadap keberhasilan free throw jika jika tidak ditambah oleh factor lain seperti tinggi bola dan jarak tangan dengan ring saat melakukan free throw.

\section{Rekomendasi}

1. Karena sudut lengan yang mendekati $90^{\circ}$ belum tentu menentukan keberhasilan free throw, maka perlu factor lain juga yang diperhatikan seperti sudut tungkai, sudut lemparan dan kecepatan laju bola.

2. Bentuklah sudut tungkai antara $90^{\circ}-120^{\circ}$ dan mendekati $103,96^{\circ}$ agar mendapatkan tenaga dari tubuh bagian bawah sehingga menghasilkan bola yang masuk dalam ring.

3. Bentuklah sudut lemparan atau pelepasan bola antara $49^{\circ}-55^{\circ}$. Hal tersebut terbukti dapat menentukan keberhasilan free throw yang pada penelitian ini dibuktikan dengan hasil rata-rata besarnya sudut lemparan free throw yang berhasil masuk sebesar 53,23, sedangkan yang gagal sebesar $55,07^{\circ}$. 
4. Apabila akan melakukan tembakan dengan kecepatan tertentu, maka perhatikan tinggi bola dan jarak tangan dengan ring saat melakukan free throw

\section{Daftar Pustaka}

Ambler, Vic. 2008. Bola Basket. Bandung : CV. Pionir Jaya.

Arikunto, Suharsimi. 2010. Prosedur Penelitian Suatu Pendekatan Praktik. Jakarta : PT. Asdi Mahasatya

FIBA. 2010. Peraturan Resmi Bola Basket 2010. (online), (http://www.fiba.com/downloads/Rules/201 0/OfficialBasketballRulles2010.pdf, diakses pada tanggal 6 Maret 2017).

Hay, James. 1978. The Biomechanics of Sport Technichs. New Jersey : Prentice-Hall International Edition.

Horongbala, Rastafari, dkk. 2005. Coaching Basketball Fundamental Penataran Pelatih Tingkat Dasar. Jakarta : PB PERBASI.

Hudson, J. 1982. A Biomechanical Analysis by Skill Level of Free Throw Shooting in Basketball. Makalah disajikan dalam Simposium Internasional Biomekanik Olahraga, San Diego, California.

Kosasih, Danny. 2008. Fundamental Basketball First Step To Win. Semarang. Karang Turi Media.
Noor, Juliansyah. 2011. Metodologi Penelitian: Skripsi, Tesis, Disertasi, dan Karya Ilmiah. Jakarta : Kencana.

Oliver, Jon. 2007. Dasar-Dasar Bola Basket. Eastern Illinois University : Pakar Raya.

Pramana, Bangun Yuda. 2013. Tinjauan Kondisi Fisik Atlet Bolabasket SMAN 3 Payakumbuh. (online), (http://bangunyuda.files.wordpress.com/20 13/09/jurnal.pdf, diakses pada tanggal 26 Juni 2017).

Pribadi, Heri Purnama. 2013. Analisis Keberhasilan Shooting 3 Point Pada Team Bolabasket Putra IKOR UNESA. Skripsi Tidak Diterbitkan. Surabaya : Universitas Negeri Surabaya.

Saebani, Beni A. 2008. Metode Penelitian. Bandung : CV Pustaka Setia.

Soetjipto. 2010. Profil Pukulan Netting pada Pelatihan Bulu Tangkis di Club Citra Raya Unesa. Jurnal Ilmu Keolahragaan. Vol, 6. No, 2. Hal, 1-8.

Wissel, Hall. 2000. Basketball Step to Success: Sports Instruction Series. Second Edition. United States of America: Human Kinetics.

Wissel, Hall. 1996. Bolabasket: Langkah Untuk Sukses. Jakarta : PT Raja Grafindo Persada 